\title{
The Evaluation of Storage Life when Disordered Data Appear in Accelerated Performance Degradation Tests
}

\author{
X.S. Li \\ Yichang Testing Technique Research Institute \\ Hubei, China
}

\begin{abstract}
Motivated by the fact that disordered data may appear in accelerated performance degradation tests when the sample is small, a new storage life evaluation method is proposed to mining information from the existing data. Combining the knowledge that the mean value of the performance parameter will degrade, isotonic regression are used to order the data. Meanwhile, the variance of the parameter is revised by mechanism consistency boundary. Finally, with the ordered data, linear degradation model and accelerated model are used to evaluate the storage life. The prediction method is applied to a battery's data which contains disordered data from accelerated performance degradation tests as example and works well.
\end{abstract}

Keywords--disordered data; storage life; isotonic regression; mechanism consistency

\section{INTRODUCTION}

Due to the fact that reliability and life of products is higher and longer, products show few or no failure in accelerated life tests (ALT) [1]. Thus that accelerated degradation tests (ADT) which cover more products life and reliability information is widely performed [2]. For those products in the design phase or with the limits of test funds, the sample size is small. And it will be smaller when coping with destructive measurement [3]. Small sample lead to the appearance of disordered data and traditional method is not functioning well. In this context, we propose an improved storage life evaluation method to deal with testing data when disordered data exists.

As for the method in this article, we firstly order the data with knowledge that the mean value of the performance parameter will degrade. So we use Pool Adjacent Violators Algorithm (PAVA) to obtain the Maximum Likelihood Estimation (MLE) of the isotonic regression under semi order restriction $[4,5,6]$. Then, mechanism consistency boundary for accelerated degradation testing is used to revise the estimation of variance [7]. Obtaining the mean value and variance of the performance parameter, we use the percentile of each measuring time to fit the linear degradation model and predict pseudo life by relative threshold in each accelerated stress [8]. At last, linear accelerating model is used to extrapolate the storage life at normal stress. The proposed method is very productive and already applied to the evaluation of storage life of our battery.

\section{THE MLE OF ISOTONIC REGRESSION}

Assume that $\left(x_{i}, y_{i 1}\right),\left(x_{i}, y_{i 2}\right), \ldots,\left(x_{i}, y_{i n_{i}}\right), i=0,1,2, \ldots, q$ is the performance $y_{i j}$ collected from one accelerated stress of the accelerated performance degradation tests at measuring time $x_{i}$. $x_{0}$ stands for the stage before accelerated tests. Use PAVA algorithm, the method to obtain the MLE of the performance data isotonic regression under semi order restriction where $\mu_{0} \geq \mu_{1} \geq \cdots \geq \mu_{q}$ is show in the following steps:

a) Let

$$
\hat{\mu}_{i}=\frac{1}{n_{i}} \sum_{j=1}^{n=n_{i}} y_{i j}
$$

$\hat{\sigma}_{i}^{2}=\frac{1}{n_{i}-1} \sum_{j=1}^{n=n_{i}}\left(y_{i j}-\hat{\mu}_{i}\right)^{2}, w_{i}=\frac{n_{i}}{\hat{\sigma}_{i}^{2}}, i=0,1,2, \ldots, q$;

b) If $\mu_{0} \geq \mu_{1} \geq \cdots \geq \mu_{q}, \mu^{*}=\left(\hat{\mu}_{0}, \hat{\mu}_{1}, \cdots, \hat{\mu}_{q}\right)$;

c) If $m$ exists so that $\mu_{m} \leq \mu_{m+1}$, let $B=\{m, m+1\}$ and $\mu_{B}=A v(B)=\sum_{i \in B} \mu_{i} w_{i} / \sum_{i \in B} w_{i} \quad, \quad w_{B}=w_{m}+w_{m+1} \quad$. Thus consistent $\quad \tilde{\mu}=\left(\hat{\mu}_{0}, \hat{\mu}_{1}, \cdots, \hat{\mu}_{j-1}, \hat{\mu}_{B}, \hat{\mu}_{j+2}, \cdots, \hat{\mu}_{q}\right) \quad$, $\tilde{w}=\left(w_{1}, w_{2}, \cdots, w_{j-1}, w_{B}, w_{j+2}, \cdots, w_{q}\right)$

d) Repeat step III until finding $B_{1}, B_{2}, \ldots, B_{k}$ to meet that $A v\left(B_{1}\right) \geq A v\left(B_{2}\right) \geq \cdots \geq A v\left(B_{k}\right)$. So we have $\mu_{i}^{*}=A v\left(B_{t}\right), i \in B_{t}, t=1,2, \ldots, l$

\section{VARIANCE REVISION}

In the assumption of normal distribution, mechanism consistency boundary for accelerated degradation testing is that the Coefficient of Variation (CV) of the performance at all the measuring time is consistent, namely $\mu_{i} / \sigma_{i}^{2}=c$, in which $\mathrm{c}$ is a constant. Use the MLE result of isotonic regression to fit the revise equation $\sigma^{2}=(1 / c) \cdot \mu$. Use Least Squares (LS) estimator of $c$ to revise the variance based on the mean value at each measuring time, namely: 


$$
\left(\sigma_{i}^{2}\right)^{*}=\frac{1}{\hat{c}} \mu_{i}^{*}, i=0,1,2, \ldots, q
$$

\section{ESTIMATION OF PSEUDO LIFE}

Firstly, calculate the percentile of each measuring time. The lower $p$ percentile at each measuring time can be estimated as follows:

$$
y_{i p}=\mu_{i}^{*}+u_{p} \sigma_{i}
$$

In which $u_{p}$ is the standard normal deviator.

Secondly, let the percentile fit the linear degradation model $L=\alpha+\beta t$ and obtain the $\operatorname{LS}$ estimation $\hat{\alpha}$ and $\hat{\beta}$. Thus the pseudo life can be estimated by relative threshold $K$ in the following equation:

$$
t^{*}=\frac{K \hat{\alpha}}{|\hat{\beta}|}
$$

\section{EXTRAPOLATION}

Use the method in chapter 2, 3 and 4 to deal with the data from accelerated degradation test and obtain the pseudo life at each accelerated stress level. And use the following linear accelerated model to extrapolate the storage life at usage stress:

$$
\ln \xi=a+b \varphi(S)
$$

In which $\xi$ is the characteristic parameter of the lifetime and $\varphi(\bullet)$ is the known function related to the stress level and from the physical theory or engineering practice.

As for the estimation of $a$ and $b$, the LS estimation can be used.. If there are not enough groups of tests, $m \leq 3$, the parameter $b$ can be fixed first by previous knowledge because parameter $b$ is only related to the failure mechanism. Assume that the product is tested at $m$ accelerated stress level When $b$ is fixed as $\hat{b}, a$ can be estimated by the following equation:

$$
\hat{a}=\arg \min \sum_{i=1}^{m}\left(\ln \xi_{i}-\left(a+\hat{b} \varphi\left(S_{i}\right)\right)\right)^{2}
$$

In this way, the storage life of the $\mathrm{p}$ percentile can be evaluated by the following equation at normal storage stress $S_{0}$ :

$$
\xi=\exp \left(\hat{a}+\hat{b} \varphi\left(S_{0}\right)\right)
$$

\section{APPLICATION}

We test a kind of disposable battery, whose model number is CR17335, at two accelerated temperature level. We measured the battery capacity after each 28 -day test to indicate the failure of battery for that the capacity will degrade during storage. The following table contains the capacity that the factory provided.

TABLE I. BATTERY CR17335 FACTORY CAPACITY.

\begin{tabular}{|l|l|l|l|l|l|}
\hline \multicolumn{6}{|l}{ Battery CR17335 Factory Capacity /mAh } \\
\hline 1245 & 1176 & 1056 & 1082 & 1143 & 1131 \\
\hline 1290 & 1078 & 1116 & 1108 & 1020 & 1134 \\
\hline 1231 & 1156 & 1089 & 1252 & 1003 & 1091 \\
\hline 1092 & 1175 & 1085 & 1131 & 1115 & 1036 \\
\hline 1171 & 1073 & 1077 & 1119 & 1093 & 1059 \\
\hline
\end{tabular}

Use the factory data to perform a Jarque-Bera test and accept that the capacity obey the normal distribution with probability $0.1082(\geq 0.05)$. The accelerated tests data under $65^{\circ} \mathrm{C}$ and $75^{\circ} \mathrm{C}$ shows in the Table 2 and Figure 1 and 2 .

TABLE II. ACCELERATED DEGRADATION TESTS DATA.

\begin{tabular}{|l|l|l|l|l|l|l|}
\hline \multirow{2}{*}{$\begin{array}{l}\mathrm{T} / \\
{ }^{\circ} \mathrm{C}\end{array}$} & \multicolumn{6}{|l|}{ Capacity $/ \mathbf{m A h}$} \\
\cline { 2 - 7 } & $\begin{array}{l}1^{\text {st }} \\
\text { stage }\end{array}$ & $\begin{array}{l}2^{\text {nd }} \\
\text { stage }\end{array}$ & $\begin{array}{l}3^{\text {rd }} \\
\text { stage }\end{array}$ & $\begin{array}{l}4^{\text {th }} \\
\text { stage }\end{array}$ & $\begin{array}{l}5^{\text {th }} \\
\text { stage }\end{array}$ & $\begin{array}{l}6^{\text {th }} \\
\text { stage }\end{array}$ \\
\hline \multirow{2}{*}{65} & 936.7 & 1027.3 & 910.5 & 839.5 & 806.5 & 997.1 \\
\cline { 2 - 7 } & & 938.1 & 965.9 & 752.3 & 807.9 & 929.2 \\
\cline { 2 - 7 }${ }^{\circ} \mathrm{C}$ & 901.8 & 920.9 & 820.5 & 925.7 & & \\
\cline { 2 - 7 } & 904.2 & 892.6 & 913.7 & 953.2 & & \\
\hline 75 & 985.5 & 925.1 & 993.6 & 1021.6 & 1024.4 & \\
${ }^{\circ} \mathrm{C}$ & 9 & & & & & \\
\hline
\end{tabular}

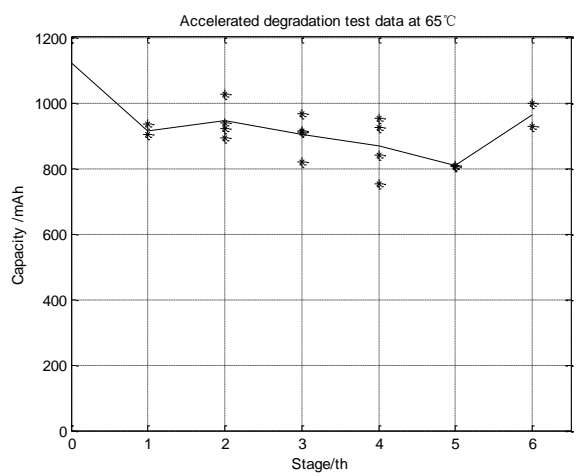

FIGURE I. ACCELERATED DEGRADATION TEST DATA AT $65^{\circ} \mathrm{C}$.

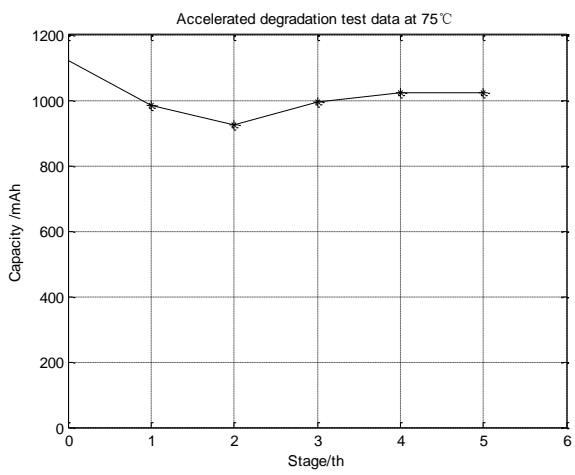

FIGURE II. ACCELERATED DEGRADATION TEST DATA AT $75^{\circ} \mathrm{C}$. 
Use the method in chapter 2 to obtain the MLE of the performance data isotonic regression under semi order restriction $\mu_{0} \geq \mu_{1} \geq \cdots \geq \mu_{q}$. For the reason that there is only one sample at each stage at $75^{\circ} \mathrm{C}$, we can set the variance from factory data. After PAVA algorithm, revise the variance by the method in chapter 3 . The result is listed in the Table 3.

Calculate the $10 \%$ percentile of each stage to fit the linear degradation model $L=\alpha+\beta t$ and we set the relative threshold as the percentile capacity descend $15 \%$, the pseudo life can be estimated as show in the Table 4.

TABLE III. THE MLE OF THE ISOTONIC REGRESSION AND THE REVISED VARIANCE.

\begin{tabular}{|c|c|c|c|c|c|c|c|c|}
\hline \multirow{2}{*}{\multicolumn{2}{|c|}{$\mathrm{T} /{ }^{\circ} \mathrm{C}$}} & \multicolumn{7}{|c|}{ Capacity /mAh } \\
\hline & & \multirow{2}{*}{$\begin{array}{c}\text { Factory } \\
1120.9\end{array}$} & \multirow{2}{*}{$\begin{array}{l}1^{\text {st }} \\
\text { stag } \\
\text { e } \\
988 . \\
3 \\
\end{array}$} & \multirow{2}{*}{ 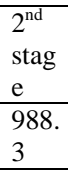 } & \multirow{2}{*}{ 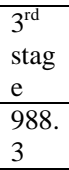 } & \multirow{2}{*}{$\begin{array}{l}4^{\text {th }} \\
\text { stag } \\
\text { e } \\
988 . \\
3 \\
\end{array}$} & \multirow{2}{*}{ 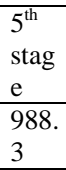 } & \multirow{2}{*}{$\begin{array}{l}6^{\text {th }} \\
\text { stag } \\
\text { e }\end{array}$} \\
\hline \multirow{2}{*}{75} & $\mu$ & & & & & & & \\
\hline & $\sigma$ & 45.7 & 42.9 & 42.9 & 42.9 & 42.9 & 42.9 & \\
\hline \multirow{2}{*}{65} & $\mu$ & 1120.9 & $\begin{array}{l}918 . \\
2\end{array}$ & $\begin{array}{l}918 . \\
2\end{array}$ & $\begin{array}{l}902 . \\
6\end{array}$ & $\begin{array}{l}867 . \\
7\end{array}$ & $\begin{array}{l}807 . \\
3\end{array}$ & $\begin{array}{l}807 \\
.2\end{array}$ \\
\hline & $\sigma$ & 84.1 & 76.1 & 76.1 & 75.5 & 74.0 & 71.4 & \\
\hline
\end{tabular}

TABLE IV. ESTIMATION OF PSEUdo LIFE.

\begin{tabular}{|l|l|l|l|}
\hline Temperature & Degradation model & $\begin{array}{l}\text { Correlation } \\
\text { coefficient }\end{array}$ & $\begin{array}{l}\text { Pseu } \\
\text { do } \\
\text { life } \\
\text { /year } \\
\text { s }\end{array}$ \\
\hline $75^{\circ} \mathrm{C}$ & $L=1000.908-240.1$ & $r^{2}=0.4286$ & $\begin{array}{l}0.62 \\
50\end{array}$ \\
\hline $65^{\circ} \mathrm{C}$ & $L=932.413-535.15$ & $r^{2}=0.7784$ & $\begin{array}{l}0.26 \\
13\end{array}$ \\
\hline
\end{tabular}

Assume that normal storage temperature is $25^{\circ} \mathrm{C}$ and $20^{\circ} \mathrm{C}$. According to the engineering practice- 'testing at $55^{\circ} \mathrm{C}$ for 28 days equals one-year normal storage', we can get that $\hat{b}=8373.9$ using Arrhenius model $\ln \xi=a+b / T$ at $25^{\circ} \mathrm{C}$. Because parameter $b$ is only related to the failure mechanism, the $b$ is fixed. Use the pseudo life at $65^{\circ} \mathrm{C}$ and $75^{\circ} \mathrm{C}$ to estimate parameter $a$. The rest at $20^{\circ} \mathrm{C}$ may be deduced by analogy. Use the accelerated model to extrapolate the storage life at usage stress. Result is shown in the Figure 3 and Table 5.

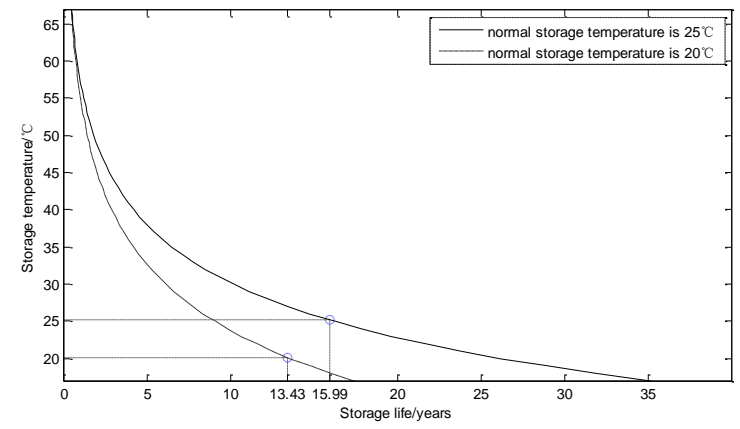

FIGURE III. USE ACCELERATED MODEL TO EXTRAPOLATE STORAGE LIFE.

TABLE V. STORAGE LIFE PREDICTION.

\begin{tabular}{|l|l|l|}
\hline $\begin{array}{l}\text { Normal } \\
\text { storage } \\
\text { temperature }\end{array}$ & Accelerated model & $\begin{array}{l}\text { Storage life } \\
\text { /years }\end{array}$ \\
\hline $25^{\circ} \mathrm{C}$ & $\ln \xi=-25.314+8373.924 / T$ & 15.99 \\
\hline $20^{\circ} \mathrm{C}$ & $\ln \xi=-21.477+7057.280 / T$ & 13.43 \\
\hline
\end{tabular}

Use the method we proposed, we can evaluate the storage life is 15.99 years when normal storage temperature is $25^{\circ} \mathrm{C}$ and 13.43 years when normal storage temperature is $20^{\circ} \mathrm{C}$.

\section{REFERENCES}

[1] Y.B. Zhang, H.M. Fu, Z.H. Wang, Method for reliability analysis on constant-stress zero-failure accelerated life test. Journal of Aerospace Power, 28(3), pp. 520-524, 2013.

[2] Meeker W. Q., Escobar L. A., Lu C. J. Accelerated degradation tests: modeling and analysis. Technometrics, 40(2), pp. 89-99, 1998.

[3] Escobar L. A., Meeker W. Q., Kugler D. L., et al. Accelerated destructive degradation tests: data, models, and analysis. Mathematical and Statistical Methods in Reliability, pp. 319-338, 2003.

[4] N.Z. Shi, Isotonic Regression and Its Maximum Likelihood Estimation. Chinese Journal of Applied Probability and Statistics, 9(2), pp. 203-215, 1993.

[5] N.Z. Shi, H. Jiang. Maximum likelihood estimation of isotonic normal means with unknown variances. Journal of multivariate analysis, 64(2), pp. 183-195, 1998.

[6] Lee CIC. The quadratic loss of isotonic regression under normality. The Annals of Statistics, 686-688, 1981.

[7] F.C. Lin, Q.C. Wang, Y.X. Chen, et al. Pseudo-life-based test method of mechanism consistency boundary for accelerated degradation testing. Journal of Beijing University of Aeronautics and Astronautics, 38(2), pp. 233-238, 2012.

[8] X.B. Ma, J.Z. Wang, Y. Zhao, Reliability assessment using constantstress accelerated degradation data based on pseudo life distribution. Systems Engineering and Electronics, 33(1), pp. 228-232, 2011 